\title{
Neuroparenting: the Myths and the Benefits. An Ethical Systematic Review
}

\author{
Anke Snoek (D) Dorothee Horstkötter
}

Received: 8 April 2021 / Accepted: 15 August 2021 / Published online: 27 September 2021

(C) The Author(s) 2021

\begin{abstract}
Parenting books and early childhood policy documents increasingly refer to neuroscience to support their parenting advice. This trend, called 'neuroparenting' has been subject to a growing body of sociological and ethical critical examination. The aim of this paper is to review this critical literature on neuroparenting. We identify three main arguments: that there is a gap between neuroscientific findings and neuroparenting advice, that there is an implicit normativity in the translation from neuroscience to practice, and that neuroparenting is a form of neoliberal self-management. We will critically discuss these arguments and make suggestions for ethically responsible forms of neuroparenting that can foster child development but avoid pitfalls.
\end{abstract}

Keywords Neuroparenting · Parenting ·

Neoliberalism · Early childhood policies $\cdot$ Ethical review $\cdot$ Child development

\section{Introduction}

Many parents seek advice, to determine how to best raise their children or deal with challenges they

\section{A. Snoek $(\bowtie) \cdot$ D. Horstkötter}

Department of Health, Ethics and Society (HES),

Maastricht University, Metamedica, Postbus 616,

6200 MD Maastricht, Netherlands

e-mail: A.snoek@maastrichtuniversity.nl encounter. In the last decade, parenting advice based on neuroscientific evidence has become so popular, that some speak of neuroparenting [1]. Neuroparenting is a parenting style where neuroscientific insights are used to improve parenting, and thereby to foster child development. The idea behind it is twofold: 1) neuroscientific evidence can provide essential insights in how parental choices can positively or negatively influence child brain development, 2) Knowledge about children's brain development allows parents to adjust their parenting to their child's developmental stage $[1,2]$. Examples of neuroparenting range from the advice to stimulate your newborn's brain development by reading or breastfeeding [3] to parenting books on the 'teenage brain' to support parents in managing adolescents' lack of self-control [4].

This emerging trend of neuroparenting fits into a broader development of the neuroscientification of the discourse on child and youth development [5]. It can be observed in both popular parenting books as in policy documents on how to support child development [6].

The rise of neuroparenting has also triggered an engaged and critical social and ethical discussion regarding its implications on child development, on parent-child relationships, and on identity. To date, a stalemate seems to have emerged between those who aim to invoke neuroscientific research for parenting and parenting support and those who are critical about this endeavor. This stalemate leads to a situation where neuroscientific findings get either over-claimed 
in their practical usability or abandoned altogether as a source of insight. In order to overcome this stalemate, the current article will review the sociological and ethical literature on neuroparenting. The aim is to identify and evaluate the reasons that have been given for and against the practice of neuroparenting.

\section{Method}

Systematic reviews are comparatively new to ethics studies, but provide a particularly powerful way to systematically identify, analyze and synthesize normative argumentation [7, 8]. We conducted a search of relevant keywords on $2^{\text {nd }}$ February 2020 in Google scholar, Pubmed, Psycinfo, Philpapers, and Jstor. We started with the rather broad term 'neuroparenting', and continued the search using 'brain-based parenting' as an alternative, because several search engines (PsychInfo, Philpapers, and Jstor) yielded only one result or none at all. In addition, we evoked snowballing methods and searched the references of selected article for further hints. Articles were scanned on title and abstract, and if in doubt, content.

Given that our main point of interest is the debate on neuroparenting, we excluded primary sources: empirical neuroscientific findings; parenting books and their reviews. We also excluded literature on neuroeducation and neuroenhancement because these typically address professional educators, not parents and because they focus on cognitive development rather than child development more broadly. Also non-English articles were excluded (Fig. 1).

We identified 37 articles that critically discuss the phenomenon of neuroparenting. A qualitative analysis of the articles was conducted using Nvivo10, a software package designed to analyse qualitative data, but that is also used for literature reviews. We uploaded pdfs of the articles and linked a label with a description (node) to the arguments we encountered. We then grouped and synthesized the different nodes. That way it became apparent how certain ethical themes and categories reemerge across different practices of neuroparenting (Table 1).

\section{Field Analysis: Age Groups, Aims, Dissemination and Methods}

We found that the critical sociological and ethical literature uses diverse methodologies, focussed on the different ways in which neuroparenting advice is disseminated, and focused on different age-group with different intervention aims. This analysis resulted in the following field map (Fig. 2).

Neuroparenting advice - and hence the critical literature - focuses on three age groups: 1) the 'first three years', measured from conception, 2) young children in general, and 3) adolescents [4, 9-11]. For these age groups, different overlapping neuroparenting aims were identified. Regarding children's early years, the main focus is on improving social-emotional development, mediated by adequate bonding and love, and on optimizing cognitive development and IQ. Neuroparenting early in life is also based on the hope that psychological problems or even criminal behavior later in life can be prevented enabling children to grow into productive citizens [2]. For adolescents we found the focus was on both ways to control unruly, criminal, or violent behavior $[10,11]$ and also on enabling adolescents to reach their full potential, cognitively, socially and creatively [4].

Neuroparenting was found to be disseminated through various routes, most notably public policies, media, and the promotion of direct-to-consumerproducts like toys or parenting books. With regard to the dissemination of neuroparenting directly to consumers, the studies focus on parenting books $[4,12]$, flash cards [13], or educational toys for children [14].

Methodologically, most critical sociological and ethical studies focused on the content-analysis of policy documents, media articles, or parenting materials $[6,15,16]$. Some studies used a more sociological analysis, exploring parenting norms [12, 14, 17]. Others used a qualitative empirical design that give insight into the experiences of parents [4, 13, 18-21], adolescents [9], or policy makers [15, 22]. Two studies had as primary target to review neuroscientific literature on which the neuroparenting advice are based $[23,24]$. 


\section{Identification of studies via databases and registers}

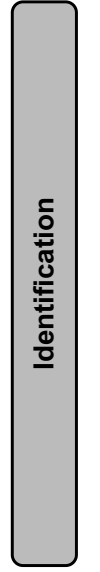

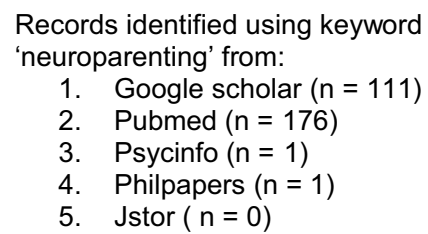

Records identified using keyword 'neuroparenting' from:

1. Google scholar $(n=111)$

2. Pubmed $(n=176)$

3. Psycinfo $(n=1)$

4. Philpapers $(n=1)$

5. Jstor $(n=0)$

Records identified using keyword 'brain parenting' from:

6. Google scholar $(n=$ 228.000)

7. Pubmed $(n=1032)$

8. Psycinfo $(n=111)$

9. Philpapers $(n=996)$

10. Jstor $(n=3340)$

Record identified through scanning literature of selected articles:

11. $n=33$
Duplicate records removed before screening:

1. $n=6$ (5 referred to separate book chapters of Macvarish Monography. We only included the monography)

2. $\mathrm{n}=32$

3. $n=1$

4. $\mathrm{n}=1$

5. $\mathrm{n}=0$

Records identified using keyword 'brain parenting' from:

6. Google scholar ( $n=228.000$ key word too broad $)$

7. Pubmed ( $n=1032$ key word too broad)

8. Psycinfo $(n=108)$

9. Philpapers $(n=996$ key word too broad)

10. Jstor $(n=3340$ key word too broad)

If the first 50 pages revealed no useful hit, the keyword was considered too broad, and the rest of the pages were not screened

Record identified through scanning literature of selected articles: 11. $n=0$
Records excluded**

Reason: non English $(n=7)$

Reason: Book review $(n=5)$

Reason: Parenting books ( $\mathrm{n}=7$ )

Reason: Only minor reference to neuroparenting $(n=114)$

Reason: medical literature on neural conditions $(n=109)$

Reports not retrieved

$(n=0)$

$n=43$

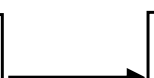

Reports excluded:

Reason: neuroeducation $(n=2)$

Reason: neuroenhancement $(n=2)$

$n=43$

Reason: focused on treatment of neural conditions $(n=2)$

Fig. 1 Search strategy literature review 
Table 1 Overview of included studies, describing title, country, methodology and which critical arguments are most prominent

\begin{tabular}{|c|c|c|c|c|}
\hline & Study & Country & Methodology & Arguments \\
\hline 1 & $\begin{array}{l}\text { Macvarish (2016) Neuroparent- } \\
\text { ing: The expert invasion of } \\
\text { family life }\end{array}$ & UK & $\begin{array}{l}\text { Sociological analysis, document } \\
\text { analysis }\end{array}$ & $\begin{array}{l}\text { Gap science practice, hidden } \\
\text { normativity, neoliberal }\end{array}$ \\
\hline 2 & $\begin{array}{l}\text { Macvarish (2014) The 'first three } \\
\text { years' movement and the infant } \\
\text { brain: A review of critiques }\end{array}$ & UK & $\begin{array}{l}\text { Review of neuroscientific litera- } \\
\text { ture }\end{array}$ & Gap science practice \\
\hline 3 & $\begin{array}{l}\text { Bruer (1999) The myth of the first } \\
\text { three years: A new understand- } \\
\text { ing of early brain development } \\
\text { and lifelong learning }\end{array}$ & US & $\begin{array}{l}\text { Review of neuroscientific litera- } \\
\text { ture }\end{array}$ & Gap science practice \\
\hline 4 & $\begin{array}{l}\text { Maxwell \& Racine (2012) Does } \\
\text { the neuroscience research on } \\
\text { early stress justify responsive } \\
\text { childcare? examining interwo- } \\
\text { ven epistemological and ethical } \\
\text { challenges }\end{array}$ & Canada & $\begin{array}{l}\text { Review of neuroscientific litera- } \\
\text { ture }\end{array}$ & Gap science practice \\
\hline 5 & $\begin{array}{l}\text { Belsky \& De Haan (2011) Parent- } \\
\text { ing and children's brain develop- } \\
\text { ment: The end of the beginning }\end{array}$ & General & $\begin{array}{l}\text { Review of neuroscientific litera- } \\
\text { ture }\end{array}$ & Gap science practice \\
\hline 6 & $\begin{array}{l}\text { Wall (2004) Is Your Child's Brain } \\
\text { Potential Maximized ?: Mother- } \\
\text { ing in an Age of New Brain } \\
\text { Research }\end{array}$ & Canada & Sociological analysis & Neoliberal \\
\hline 7 & $\begin{array}{l}\text { Wall (2010) Mothers' experiences } \\
\text { with intensive parenting and } \\
\text { brain development discourse }\end{array}$ & Canada & Empirical & Neoliberal \\
\hline 8 & $\begin{array}{l}\text { Jacobs \& Hens (2018) Love, } \\
\text { neuro-parenting and autism: } \\
\text { from individual to collective } \\
\text { responsibility towards parents } \\
\text { and children }\end{array}$ & Netherlands & Empirical & Neoliberal \\
\hline 9 & $\begin{array}{l}\text { Mackenzie \& Roberts (2017) } \\
\text { Adopting Neuroscience: Parent- } \\
\text { ing and Affective Indeterminacy }\end{array}$ & UK & Empirical & Neoliberal \\
\hline 10 & $\begin{array}{l}\text { Broer, Pickersgill \& Cunningham- } \\
\text { Burley, (2020) Neurobiological } \\
\text { limits and the somatic sig- } \\
\text { nificance of love: Caregivers' } \\
\text { engagements with neuroscience } \\
\text { in Scottish parenting pro- } \\
\text { grammes }\end{array}$ & Scotland & Empirical & Gap science practice \\
\hline 11 & $\begin{array}{l}\text { Leysen (2019) Upbringing and } \\
\text { Neuroscience. Embodied Theory } \\
\text { as a Theoretical Bridge Between } \\
\text { Cognitive Neuroscience and the } \\
\text { Experience of Being a Parent }\end{array}$ & Flemisch Belgium & Philosophy, sociological analysis & Neoliberal \\
\hline \multicolumn{5}{|c|}{ Policies } \\
\hline 12 & $\begin{array}{l}\text { Wastell (2012) Blinded by } \\
\text { neuroscience: Social policy, the } \\
\text { family and the infant brain }\end{array}$ & UK & document analysis & Gap science practice \\
\hline
\end{tabular}


Table 1 (continued)

\begin{tabular}{|c|c|c|c|c|}
\hline & Study & Country & Methodology & Arguments \\
\hline 13 & $\begin{array}{l}\text { Beddoe (2016) Questioning } \\
\text { the uncritical acceptance of } \\
\text { neuroscience in child and family } \\
\text { policy and practice: A review of } \\
\text { challenges to the current doxa }\end{array}$ & New Zealand & document analysis & Neoliberal \\
\hline 14 & $\begin{array}{l}\text { Edwards, Gillies, and Horsley } \\
\text { (2015) 'Brain science and early } \\
\text { years policy: hopeful ethos or } \\
\text { 'cruel optimism'?' }\end{array}$ & UK & Empirical/ document analysis & Neoliberal, Gap science practice \\
\hline 15 & $\begin{array}{l}\text { Broer \& Pickersgill (2015) Target- } \\
\text { ing brains, producing responsi- } \\
\text { bilities: The use of neuroscience } \\
\text { within British social policy }\end{array}$ & UK & document analysis & Gap science practice \\
\hline 16 & $\begin{array}{l}\text { Garrett (2019) Wired: Early } \\
\text { Intervention and the 'Neuromo- } \\
\text { lecular Gaze' }\end{array}$ & UK & Critical studies & Neoliberal \\
\hline 17 & $\begin{array}{l}\text { Shonkoff (2011) Science does not } \\
\text { speak for itself: Translating child } \\
\text { development research for the } \\
\text { public and its policymakers }\end{array}$ & US & Document analysis / empirical & Gap science practice \\
\hline 18 & $\begin{array}{l}\text { Wall (2018) 'Love builds brains': } \\
\text { Representations of attachment } \\
\text { and children's brain develop- } \\
\text { ment in parenting education } \\
\text { material }\end{array}$ & Canada & Document analysis & Hidden normativity \\
\hline 19 & $\begin{array}{l}\text { Wilson (2002) Brain Science, } \\
\text { Early Intervention and 'At } \\
\text { Risk' Families: Implications for } \\
\text { Parents, Professionals and Social } \\
\text { Policy }\end{array}$ & $\begin{array}{l}\text { UK, US, New } \\
\text { Zealand, South } \\
\text { Africa }\end{array}$ & Sociological analysis & $\begin{array}{l}\text { Hidden normativity, Gap science } \\
\text { practice }\end{array}$ \\
\hline 20 & $\begin{array}{l}\text { Macvarish (2014) Babies' brains } \\
\text { and parenting policy: The insen- } \\
\text { sitive mother }\end{array}$ & UK & Document analysis & Gap science practice \\
\hline 21 & $\begin{array}{l}\text { Lee, Lowe, and Macvarish (2014) } \\
\text { The Uses and Abuses of Biol- } \\
\text { ogy: Neuroscience, Parenting } \\
\text { and Family Policy in Britain. A } \\
\text { 'Key Findings' Report, Univer- } \\
\text { sity of Kent }\end{array}$ & UK & Document analysis & Gap science practice \\
\hline 22 & $\begin{array}{l}\text { Macvarish (2015) Neurosci- } \\
\text { ence and family policy: What } \\
\text { becomes of the parent? }\end{array}$ & UK & Document analysis & Gap science practice, neoliberal \\
\hline 23 & $\begin{array}{l}\text { Macvarish (2015) Biologising par- } \\
\text { enting: neuroscience discourse, } \\
\text { English social and public health } \\
\text { policy and understandings of } \\
\text { the child }\end{array}$ & UK & Document analysis & Gap science practice, neoliberal \\
\hline 24 & $\begin{array}{l}\text { Lowe \& Macvarish (2015) Grow- } \\
\text { ing better brains? Pregnancy and } \\
\text { neuroscience discourses in Eng- } \\
\text { lish social and welfare policies }\end{array}$ & UK & Document analysis & $\begin{array}{l}\text { Gap science practice, hidden } \\
\text { normativity }\end{array}$ \\
\hline
\end{tabular}


Table 1 (continued)

\begin{tabular}{|c|c|c|c|c|}
\hline & Study & Country & Methodology & Arguments \\
\hline 25 & $\begin{array}{l}\text { Leysen (2020). Neuro-stuffed } \\
\text { parenthood? Discursive con- } \\
\text { structions of good parenthood } \\
\text { in relation to neuroDiscourse in } \\
\text { Flemish social policy documents } \\
\text { addressing parents: a case study }\end{array}$ & Belgium & Document analysis & Neoliberal \\
\hline \multicolumn{5}{|c|}{ Media } \\
\hline 26 & $\begin{array}{l}\text { O'Connor \& Joffe (2013) Media } \\
\text { representations of early human } \\
\text { development: Protecting, feed- } \\
\text { ing and loving the developing } \\
\text { brain }\end{array}$ & UK & Media analysis & Gap science practice \\
\hline 27 & $\begin{array}{l}\text { O'Connor \& Joffe (2015) How } \\
\text { the Public Engages With Brain } \\
\text { Optimization: The Media-mind } \\
\text { Relationship }\end{array}$ & UK & Partly empirical & Gap science practice \\
\hline 28 & $\begin{array}{l}\text { Thompson \& Nelson (2001). } \\
\text { Developmental science and the } \\
\text { media: early brain development }\end{array}$ & US & Media analysis & Gap science practice \\
\hline \multicolumn{5}{|c|}{ Directed to consumers } \\
\hline 29 & $\begin{array}{l}\text { Nadesan (2002) Engineering the } \\
\text { Entrepreneurial Infant: Brain } \\
\text { Science, Infant Development } \\
\text { Toys, and Governmentality }\end{array}$ & US & Sociological analysis & Neoliberal \\
\hline 30 & $\begin{array}{l}\text { Thornton (2011) Neuroscience, } \\
\text { affect, and the entrepreneuriali- } \\
\text { zation of motherhood }\end{array}$ & US & Sociological analysis & Neoliberal \\
\hline 31 & $\begin{array}{l}\text { Chen (2019) Beyond black and } \\
\text { white: heibaika, neuroparenting, } \\
\text { and lay neuroscience }\end{array}$ & Taiwan & Empirical & Neoliberal \\
\hline \multicolumn{5}{|c|}{ Teenage brain } \\
\hline 32 & $\begin{array}{l}\text { Van de Werff (2017) Being a good } \\
\text { external frontal lobe: Parenting } \\
\text { teenage brains }\end{array}$ & Netherlands & Partly empirical & Gap science practice \\
\hline 33 & $\begin{array}{l}\text { Van de Werff (2018) Practic- } \\
\text { ing the plastic brain. Popular } \\
\text { neuroscience and the good life. } \\
\text { Maastricht University. (strong } \\
\text { overlap with the above article) }\end{array}$ & Netherlands & Partly empirical & Gap science practice \\
\hline 34 & $\begin{array}{l}\text { Elman (2014) Crazy by Design. } \\
\text { Neuroparenting and Crisis in the } \\
\text { Decade of the Brain }\end{array}$ & US & Analysis of parenting books & Hidden Normativity \\
\hline 35 & $\begin{array}{l}\text { Elman (2015) Policing at the } \\
\text { Synapse: Ferguson, Race, and } \\
\text { the Disability Politics of the } \\
\text { Teen Brain. (Strong overlap with } \\
\text { above article) }\end{array}$ & US & Sociological analysis & Hidden Normativity \\
\hline 36 & $\begin{array}{l}\text { Choudhury, McKinney, \& Merten } \\
\text { (2012) Rebelling against the } \\
\text { brain: Public engagement with } \\
\text { the "neurological adolescent." }\end{array}$ & UK & Empirical & Neoliberal \\
\hline
\end{tabular}


Table 1 (continued)

\begin{tabular}{llll}
\hline Study & Country & Methodology & Arguments \\
\hline 37 & $\begin{array}{l}\text { Bessant (2008) Hard wired for } \\
\text { risk: Neurological science, "the } \\
\text { adolescent brain" and develop- } \\
\text { mental theory }\end{array}$ & Sociological analysis & $\begin{array}{c}\text { Gap science practice, hidden } \\
\text { normativity }\end{array}$ \\
\hline
\end{tabular}

\section{Content analysis}

Looking at the content of the critical literature, three lines of criticism emerge. First, a gap is identified between available neuroscientific evidence and resulting neuroparenting advice. Second, when translating scientific findings into parenting advice and practice, critics point out that translators' implicit norms color this translation. The third line of criticism regards the way in which the advice is informed by and contributes to harmful neoliberal ideas of the goal of parenting.

When examining the content of the critical literature we found it useful to distinguish between three different layers. 1) The neuroscientific literature on which the neuroparenting advice is based. 2) The primary neuroparenting literature, i.e. parenting books, policy documents or media articles. 3) The critical sociological and ethical literature that evaluates the neuroparenting literature. In this review we added a fourth layer: 4) Our critical examination of the critical literature. In the following section we will mostly focus on the third layer, the critical literature itself. However, to understand and illustrate the arguments, we will also outline part of the neuroscientific literature and primary neuroparenting literature.

\section{Gap Between the Neuroscientific Evidence and Neuroparenting Advice}

Neuroparenting advice typically presents itself as directly following from neuroscientific evidence. Different scholars in the critical literature have pointed out that the translation of neuroscience to policies and parenting advice is not as straightforward as is often assumed. 'Evidence for policy making does not simply repose in journals "ready to be harvested", [25]. Science does not speak for itself, Shonkoff and Bales

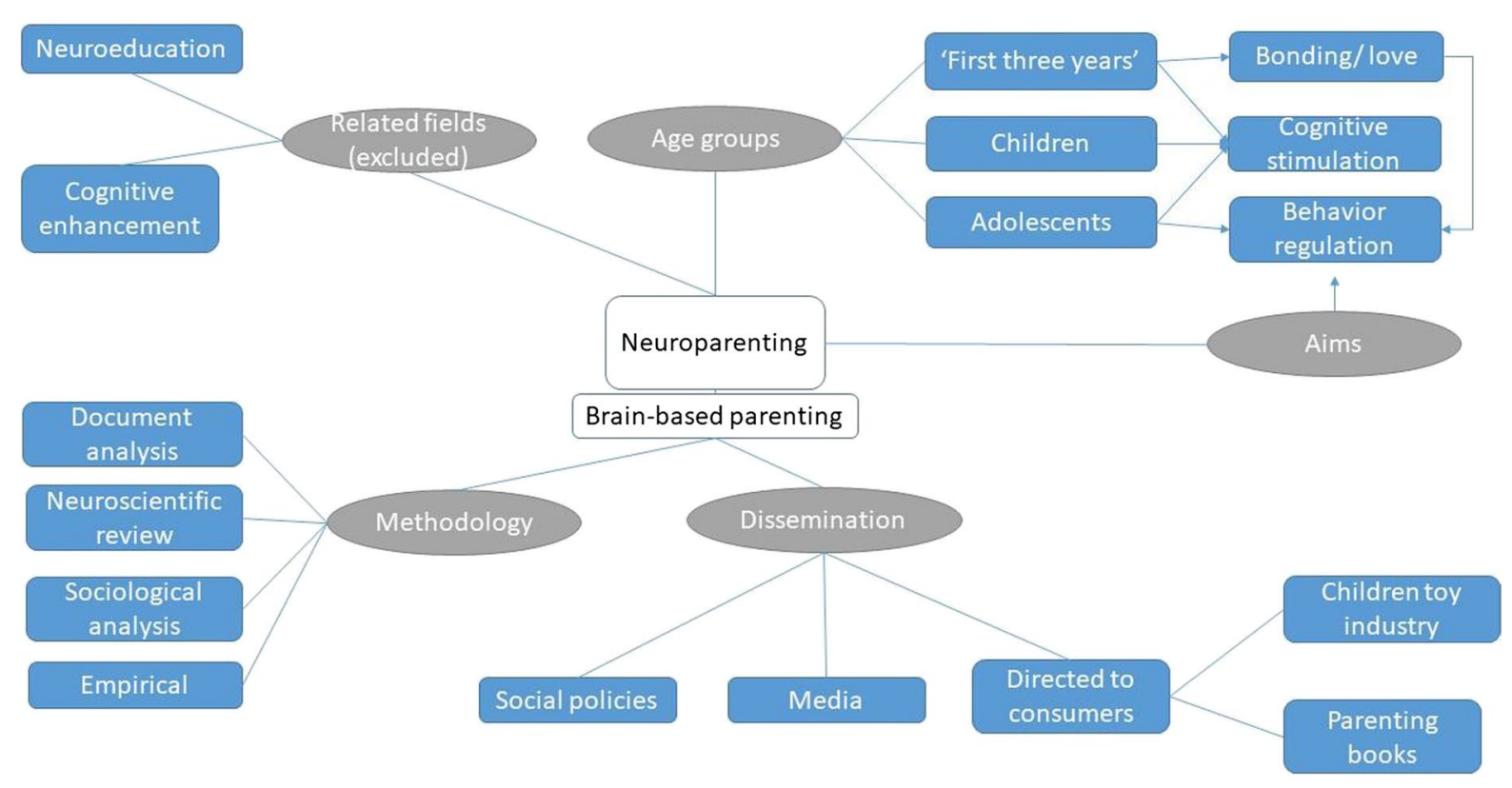

Fig. 2 Field map on critical sociological and ethical literature on neuroparenting 
(2011) warn. Translating scientific findings to practices is a skill and the following four examples show what this means.

\section{The Scientific Myth of the 'First Three Years Movement'}

One of the earliest criticisms of neuroparenting found in our study is Bruer's discussion of the "first three years" movement. Bruer, a former president of a foundation that supported research in cognitive development, child health, and brain development, noticed in the mid $90 \mathrm{~s}$ an increase in US media reports stating that new brain science was about to revolutionize child care and parenting. Bruer identified three spear point of these revolutionizing insights: i) there are critical periods - windows of opportunity - for brain development that should not be missed; ii) during these critical periods, the brain needs the right stimulation to develop well, if that does not happen, permanent damages can occur, iii) the first three years of a child's life is a period of rapid synaptic growth, hence this is an important critical period whereupon interventions should focus in order that the right stimulation occurs. He dubbed advice focused on these three spearpoints 'the first three years movement' [23]. He noted that this interpretation of the neuroscience was also informing early childhood policies.

Despite forceful claims to be based on novel scientific findings, Bruer argued that the scientific underpinning of apparent critical periods very early in life stemmed from 1) either preliminary neuroscientific findings not yet understood in behavioral terms; 2) animal studies without any obvious implications for humans or 3) pre-existing psychological theories on attachment [23]. First, he points out that the neuroscientific research appealed to described brain structures or mechanisms without detailing how these neural changes influence behavior or development. Instead the links to behavior tended to have the status of a hypothesis. In contrast those, such as policy makers, who were interpreting the neuroscience in order to develop parenting advice, jumped to unjustified conclusions. Secondly, he pointed out that research cited to support the claim that there are critical periods of brain development was done on animals and argued that its application to the human case was far from clear. For example, much cited in this movement is a study that used kittens that had been deprived of visual input in one eye from birth to three months old. Afterwards, these kittens stayed blind permanently in the deprived eye. In contrast, eye-closure in adult cats had no permanent effect [26]. While this shows that visual input in the first three months of life is necessary for the development of normal vision in cats, Bruer argues that the implications of this for parenting humans during early infancy is unclear [23]. Finally he argues that much of the advice was not based on revolutionary new brain insights, but rather on psychological theories such as attachment theory.

More generally Bruer questions the notion of vulnerability and critical periods based on neuroscience. Neuroscientific studies also present evidence that human development is a process of life-long learning, based on the plasticity of the brain [23]. Based on these observations, Bruer concluded, in 1999, that the first three years movement, so prominent in policy and media, is based on scientific myths. In an update memo from 2011, he argued this still rings true: 'The evidentiary base for claims about early brain development does not seem to be expanding, the interpretations are not improving, and the same examples, phrases, and images constantly recur.' (page 11) [1].

In a similar vein, Macvarish [1] showed that neuroscience gets invoked to support two rather opposite messages. When parenting advice is given, focus is put on the vulnerability of the developing brain and the danger of inflicting irreversible harm. However, when arguing for the adoption of early interventions, a focus on the plasticity of the brain and the reversibility of early damage gets promoted. It is argued that the neuroscience is being invoked in an instrumental way, supporting whichever political agenda is pursued, rather than setting or shaping the agenda itself.

\section{The mere rhetorical force of brain scan images for early intervention policies}

In 2002 neuroscientist Perry, who conducted research on neglect, published a harrowing image of a CTscan of the brain of a severely neglected child (cf Picture 1) [27].

This image became prominent in UK policy documents advocating early intervention, even illustrating the cover image of these reports [28, 29], However, the critical literature questions the representativeness of the image, suggesting it is used not because of its scientific validity but rather because of its rhetorical 


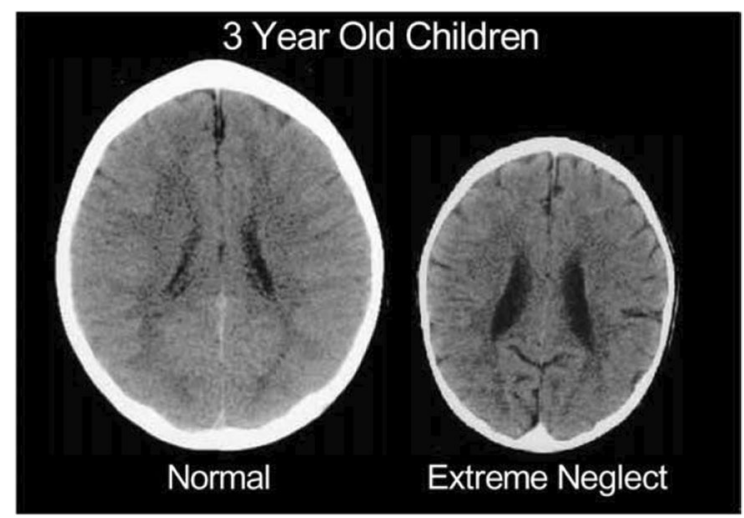

Picture 1 Perry's image of a CT scan of a healthy and extremely neglected 3 year old child (Perry 2002, p.93)

force $[25,30,31]$. It is noted that no information regarding the case history of the child in question is provided. Without this information we cannot rule out the possibility that the child might have had a massive birth trauma, or some congenital condition that caused the neglect and as a consequence the observed aberrations. The brain scan image made famous by policy makers is much less instructive than often claimed [25].

Perry's original study [2] notes that in severely neglected children only 11 out of 17 brain scans $(64.7 \%)$ were deviant. In other words more than a third were not. For children with a chaotic upbringing, but no severe neglect, only 3 out of the 26 brain scans $(11.5 \%)$ were deviant [27]. So, while some children who experience severe neglect or adverse living conditions show visible brain aberrations, many do not. Perry himself publicly objected that his work was oversimplified and misinterpreted. His findings only related to extreme neglect and not broken homes, as some politicians suggested [15]. For example the neglected child whose brain scan is depicted was locked in a basement for several years [25].

\section{The Lack of Neuroscience Behind 'Responsive Parenting'}

'Responsive parenting' is another focus of the critical literature. This is a parenting style in which parents are continuously attuned to, and promptly react to any cues of children's distress. Unresponsive parenting, by contrast, is characterized by the parent setting scheduled sleep- and feeding times, to which their children must learn to adapt. In this sense, cosleeping, feeding on demand and baby slings characterize responsive parenting, whereas sleep-training, care scheduling and (forward-facing) prams indicate unresponsive parenting. Many parenting books present neuroscientific evidence to argue that responsive parenting is the best parenting style to reduce psychological problems like anxiety in children [32].

A review by neuroscientists Lupien and colleagues [33] is frequently cited in support. They reviewed studies on the influence of stress on the brain and argue that because humans are born relatively helpless they are very dependent on caregivers, and hence babies have a stress response system that is highly attuned to environmental cues [33]. In order to reduce the activation of infant's stress system they recommend responsive parenting [33].

Maxwell and Racine [24] question the scientific evidence reviewed by Lupien and colleagues. They point out that these studies typically measure stress by elevated cortisol levels. However the link between higher cortisol levels at certain points in time and adverse behavioural outcomes is not well established and much less evidence exists for the alleged irreversibility of the effects of high cortisol levels. Moreover, the effect of responsive parenting on stress and stress reduction has not been studied at all. Therefore, they argue the claim that neuroscience shows that responsive parenting is essential for child wellbeing, is unjustifiable [24].

Macvarish [1] provides a different line of criticism, showing that 'responsive parenting' is a revival of attachment parenting that became popular during the sixties. She notes that, while it was originally promoted as one parenting style among equals, by suggesting that it has neuroscientific support, responsive parenting is presented as being best for brain development, implicitly disqualifying parents who parent differently.

\section{The Limited Neuroscience Behind Neuroparenting Advice for Enriched Environments}

Nadesan's [14] and Thornton's [12] critical examination focuses on the neuroparenting claim that enriched environments are crucial for proper brain development and the resulting industry of supposed brain stimulating toys. They argue that very little research has been done on which brain regions these 
toys stimulate nor on the long term cognitive effects they afford $[12,14]$.

For example, in 1998 the governor of Georgia, US, recommended to buy Mozart cd's for every newborn, claiming that neuroscience had shown that listening to this music stimulates babies' cognitive development $[13,16]$. However, the only study that demonstrated that listening to Mozart's sonata could improve brain performance was conducted among a small group of college students and the effect was measured on a short-term, i.e. ten minutes after listening to the music [34]. No studies had been done on babies, none had involved repeated brain measurement and no long-term positive effects of music on brain development had ever been measured. This example demonstrates how initial findings get extrapolated into claims on long-term brain development [35].

A second focus of the critical literature are dubious neuroparenting toys such as Disney's series of 'Baby Einstein' animations. These animated DVDs for babies from one month old expose them to shapes, colors, animals, music, art and even science. Disney claimed that neuroscience has shown that this supports cognitive development [12] saying in their 1997 press release: 'According to cognitive research, dedicated neurons in the brain's auditory cortex are formed by repeated exposure to phonemes, the unique sounds of language. Studies show that if these neurons are not used, they may die'. (cited in: [36]). However, research found that infants aged 8-16 months who watched the video's scored lower on language development than their peers who didn't watch animations [37]. While this negative link was contested, a positive link between language development and the mentioned animations could never be established [38] and Disney had to refund parents for providing misleading information [12].

\section{Conclusion}

In examining the criticisms focused on the translation of the science, we identified five distinct pitfalls: 1) Neuroscience is done within a specific, sometimes exceptional context, but gets uncritically translated to other groups and situations. For example, research on severe neglect gets translated into regular parenting situations. 2) Neuroscientific research often describes mechanisms, and hypothesizes what this can mean for behavior. Policy makers and the general public too quickly equate the mechanisms with behavior. 3) In this translation from mechanisms to behavior, one can easily come to different, quite opposite conclusions. For example, the neuroscientific evidence can both support theories of vulnerability as of plasticity. 4) Neuroscientific research is often static, or only describes short time effects, yet the conclusions are applied on development and long term outcomes. 5) Neuroscience is sometimes used to give existing theories more weight, instead of generating new insights. In this way, neuroscience seemed to be used more in rhetorical rather than scientific ways.

Some critical scholars think it is too early for neuroscience to inform early child policies, that the current neuroscientific results are too preliminary to usefully inform child rearing advice. 'As it turns out, the study of parenting and brain development is not even yet in its infancy; it would be more appropriate to conclude that it is still in the embryonic stage, if not that which precedes conception.' (page 410) [35]. Bruer states: 'We do not have a revolutionary, brainbased action agenda for child development', expressing the fear that the wrongful application of neuroscience will give it a bad name, preventing future research to inform policies [23]. Many scholars argue that what is currently presented as neuroscience in media and policy documents is often a caricature of neuroscience: neuromyths, neurogossip, neurobabble, brain porn, neuroscience fiction, a mythological version of the infant brain $[13,15,25,30]$. In our discussion, we will present some suggestion on how the gap can be bridged.

\section{Hidden Normativity in the Translation From} Neuroscience to Practices

The apparent gap between allegedly neuro-informed policies and neuroparenting advice and actual scientific findings, leads to a second line of argument in critical studies on neuroparenting. In the translational process from science to policy and parenting advice it is argued that preexisting normative judgments seep in $[4,16]$. Van de Werff [4] calls this phenomenon 'value work'. How we attribute meaning to scientific findings is not an objective process, but also steered by values. While this is partly inevitable because science is always a social practice impacted by cultural 
values, this does not justify biased or even discriminatory interpretation of findings [39]. However, various authors point out that the neuroscientific data is interpreted in terms of pre-existing ideas of good parenting $[1,4,10,40]$. We present here a series of examples of the interpretation of neuroscience to enforce existing power hierarchies with regard to class, ethnicity and gender in parenting. It is argued that these normative judgments tend to go unregistered because people view neuroscientific evidence as objective and unbiased.

\section{Class and Socio-Economic Status}

At first glance, neuroparenting early intervention initiatives hold a positive message. If all children get the right brain stimulation and nurturing from birth, they will no longer be held back by their social class. Neuroscience can help to give everyone an equal chance, regardless of their social-economic background [41]. Before, we showed how research on severe neglect lead to pleads for early intervention policies that focus on enriched environments and responsive parents. However, it remains unclear what this research on severe neglect means for typical households, where there is no neglect, let alone severe neglect. So far no scientific research has been done about what the threshold is for an environment that is too poor to safeguard proper brain development, and what counts as an enriched environment $[1,23]$.

Despite this lack of knowledge, popular media, policy reports, and parental educational material seems to equalize an enriched environment with a white, middle-class environment [14-16, 42]. 'Complex, enriched environments for humans end up having many of the features of upper-middle class, urban, and suburban life' ([43], page 10). For example listening to classical music, watching educational television like Sesame street, or playing with certain educational toys like Lego building blocks are presented as constituting an enriched environment. In contrast, watching Sponge Bob or listening to rap music are hardly ever presented as being part of an enriched environment [14]. Supposed neuroscience findings are being used to reinforce existing values and cultural norms, in the absence of scientific evidence on what counts as enrichment. Equating enrichment with white middle-class features suggests that people who do not value typical middle or upper-class activities are impoverishing or even neglecting their children [15]. Rather than fostering equal chances and breaking social determinism, by invoking pre-existing prejudices under the disguise of neuroscience, social differences are intensified, leading to further stigma and possible additional adverse effects for parents and children with a comparatively low social economic status [15]. 'Working-class parents, who lack the cultural capital of their middle-class counterparts, are implicitly targeted as lacking the skills to adequately stimulate and prepare their infants.' (page 423) [14].

\section{Ethnicity and Cultural Variation in Child Rearing}

Elman [10] makes a similar argument with regard to ethnicity. She studied ethnicity bias in the presentation of neuroscientific results on the so-called 'teenage brain' and the claim that generally adolescents exhibit more impulsive and more antisocial behavior than both children and adults. Current neuroscientific studies try to offer explanations for this erratic behavior, such as imbalances in the development of different brain regions and delayed development of the prefrontal cortex responsible for self-regulation and inhibition [4, 9-11].

While the neuroscientific findings actually hold for all adolescents as an age-group, Elman outlines how the same data leads to different judgements depending on one's ethnic group. When Caucasian adolescents exhibit annoying, or antisocial behavior, the tendency is to whitewash it as being age-typical because adolescents' brains are out of balance. However, when it comes to similar behavior in adolescents of color, neuroscience is not invoked to excuse it as age-congruent, but rather to argue that these youngsters' brains were wired for violence from a very early age. Youth of color get excluded from childhood innocence, and therefore are more often institutionalized [10].

Another example is cultural variation in child rearing. The research on severe neglect shows the importance of bonding, however, this concept also gets translated into a white, Western conception of ideal family life, wherein a nurturing, constantly available mother is essential [15]. This bonding, however, could likewise occur between a baby and another stable caregiver like a father, elder siblings, or grandparents. Building family policies on an Eurocentric ideal of family life and suggesting that this is backed-up by 
objective neuroscience, risks pathologizing and sanctioning culturally different but equally appropriate practices of child-rearing [15, 42].

\section{Gender}

The critical literature also points out that implicit normative ideas about gender color the interpretation of neuroscientific results. Macvarish [1] argues that neuromothering rather than neuroparenting better describes much of the advice. Two characteristics of neuroparenting contain pitfalls for reinforcing traditional gender roles: the focus on very early intervention (often prenatal) and the focus on the importance of love.

The strong focus on early intervention as prenatal puts much pressure on mothers. A Unicef brochure 'Building a happy baby', argues that parents can stimulate neural development by stroking their bump, playing music to the fetus, or reading a story to him or her [3]. While this could technically also be done by the father, it is suggested that this focus on interventions starting in uterus are more likely to be felt as a responsibility for mothers, and most of the images in the brochure contain women [1].

Jacobs and Hens [19] remark that the new, neuroscientifically imbued discourse on the importance of parental love, can largely be equated with the nineteenth century discourse on maternal love. In this discourse maternal love and nurture were presented as a kind of 'natural' state of motherhood. Thornton [12] argues that neuroparenting books encourage mothers to manage their emotions in order to ensure the emotional well-being of their children. Mothers should internalize a loving, nurturing attitude, for example, smile and look at their baby when feeding. The messages this discourse sends is an obligation to enjoy mothering, to not just act happily but sincerely be and feel happy when nurturing your child. In these parenting books, fathers and their need to manage their emotions do not even get mentioned [12].

It is also argued that this focus on mothers rather than parents is present in many educational materials on neuroparenting, and media representations of early development. Wall [42] analyzed a series of videos of a Canadian parental education campaign called 'Healthy Baby Healthy Brain'. She noticed that of the scenes depicting a parent interacting with their baby, 43 were of mothers and only seven of fathers. There is only one scene in the entire series where a father is comforting a crying baby. O'Connor and Joffe [16] analyzed 505 media articles on early development in the UK, which focused on brain development. They conclude: 'Mothers were generally positioned as the target of parenting directives, with articles often using the word 'mothers' where the gender-neutral 'parents' would have also been appropriate' (page 304). Critics point out that neurodevelopmental research is often used to reinforce traditional gender roles.

\section{Summary}

In this strand of the critical literature we can see how the translation of neuroscientific findings to practices and parenting advice is not a clear-cut top down infusion of science, but happens in interaction with preexisting values and norms. Although the reference to neuroscientific literature suggests that an objective basis had been established to distinguish between good and bad, normal and abnormal parenting [44], the advices mostly echo existing ideas about class, ethnicity, and gender. Biologising these differences in class, ethnicity and gender risks that already vulnerable groups might be further stigmatized instead of helped, increasing existing inequalities.

\section{Neuroparenting as a Form of Neoliberal Self-Management}

The final form of criticism of neuroparenting we identified is that it is part of a neoliberal tradition in which individuals are increasingly held responsible for their own success and that of their children. As "neoliberal' can mean various things, we cite some definitions from the critical literature on neoliberalism: a tradition in which 'individual self-management, selfenhancement, and personal responsibility' are key points [45]; 'body/ self-maintenance have become the new duties of the neoliberal citizen where, by looking after oneself one avoids being a financial liability to the state' [44]; 'entrepreneurial models of self-conduct' [12]. These definitions point towards a culture of capitalistic self-improvement.

Neuroparenting is analysed as a form of governmentality, in which people internalize certain norms to become productive citizens $[1,6,12,14$, 45]. It is suggested that the neoliberal norms behind 
neuroparenting advice includes claims that children's brain are highly malleable, that it is parents' responsibility to properly form their children's brains, and that parents are blameworthy when things go wrong [1]. This has been criticized on three accounts.

\section{Tension Between Individual Interests of Child Wellbeing and Societal Economic Interests}

Neuroparenting holds a promise of bettering children's lives by providing them better cognitive and social emotional development. However, several scholars have pointed towards an apparent difference between what parents think 'better lives for children' means, and what governments have in mind [14, 19]. While parents aim to see their children becoming smart, social and happy, for governments ensuring social-emotional and cognitive development of children rather seems to be a means to raise more productive citizens, and reduce antisocial behaviour [6, 12 , $14,19]$. The main goal of early interventions hence might not be family wellbeing, but prevention of children becoming a burden to society [14, 44, 45].

For example UK early intervention policies often refer to the economist Heckman who explicitly linked child development to societal costs [44]. By training parents to take care of their children's brains, better citizens can be formed. The titles of relevant policy reports reflect this attitude. For example: 'Good Parents, Great Kids, Better Citizens' [2], or 'Early Intervention: Smart Investment' [28]. Early brain intervention will save the taxpayer money [22].

It is argued that through a process of medicalization, expert invasion, surveillance, and a shift from societal to personal responsibility, governmental norms of productivity get internalized by parents. Neuroparenting advice tends to medicalize normal development, such as bonding with one's baby, or the changes during adolescence: 'Neuroparenting formed one of rehabilitative citizenships' lifelong treatment regimes for chronic youth'. ([10] p. 135) This rhetoric of medicalization justifies formal surveillance and intervention in young people's lives [14]. Several authors in the critical literature conclude that the main purpose of neuroparenting would be to train parents in entrepreneurial self-governance to deliver better citizens [12, 14, 15, 44]. Taking care of one's own and one's children's brains becomes the new duty of neoliberal citizens to avoid becoming a financial burden to the state $[15,44,46]$.

\section{An Unjustifiable Amount of Responsibility Attributed to Parents}

Neuroparenting advice is also criticized for its ideas on malleability; that life can be orchestrated and that children can become whatever they want to if only their brains are stimulated early and intensively [47]. The UNICEF brochure entitled 'Building a happy baby' [3] (emphasis by the authors) expresses this idea rather clearly, suggesting that raising a child is comparable to building a house. This triggers the concern that whenever children do not perform as intended, parents can be held personally responsible.

O'Connor and Joffe [20] found in their analysis of media articles on early development that various phenomena, like psychiatric disorders, obesity, alcoholism, and even sexual orientation are presented as direct consequences of 'prenatal events impacting on the fetal brain' (p.5) [16]. The Sun, for example released the following header: 'Pregnant women can impair their unborn tot's IQ by eating liquorice, researchers have warned.' (7 October 2009). The critical literature outlines that warnings like these can put strong pressure on (prospective) parents, particularly mothers, to ensure that they do not disrupt fetal brain development [16]. As a consequence, there is an everstronger focus on the choices of individual parents and less acknowledgment of the wider social factors that also influence development.

The critical literature points out that, based on the neuroparenting trend, government programs indeed increasingly invest in individual parent-training, while disinvesting in social support networks, like good and affordable preschools or daycare [1, 45]. This is especially hard on parents who are living in relative poverty. The hopeful ethos neuroscience seemed to entail - that all children, with the right brain stimulation could overcome social adversities - runs the risk to turn into a cruel understanding of success according to which people who do not succeed should take the blame for their failure [15].

For comparatively well-settled middle-class parents a focus on malleability in the context of a competitive society can also have detrimental effects. The critical literature outlines that neuroparenting is particularly popular among high- and middle-class 
parents. They have the resources to buy the 'right' toys, books, and other brain stimulating tools [1, 13]. However, these run the danger of changing responsive parenting within a normal range, into behavior that better would be called hyper-parenting, intensive parenting or even paranoid parenting [48]. These types of parenting are very time-consuming, and parents and children can experience this as stressful, while it is unclear whether this extra stimulation is beneficial $[13,48]$.

For example Wall [18] described how Canadian mothers are training their kindergarten-aged children in primary school subjects. They do so not only to ensure that their children have a better start once they go to school, but also because of the continuous media attention on how to boost one's child's brain development and an increasing pressure among middle-class parents to engage in these efforts. As a consequence, parents are constantly afraid that their offspring might trail behind, believing other parents train their children more. Parents themselves, however, describe this kind of hyper-parenting as stressful, demanding, and occurring at the cost of their own wellbeing [18]. In the end, it might undermine rather than increase well-being.

Chen [13] described the popularity of flashcards on a private maternity ward in Taiwan. These heibaika cards contain black and white silhouettes of animals and everyday objects and they claim to stimulate brainpower of infants below three months. Chen interviewed parents of newborns who stayed at the ward. One parent reported keeping her newborn awake for up to one hour to train her with the cards. However, there is no scientific evidence that these cards stimulate newborn's brain development, nor that this has any long-term positive effect. Instead, the popularity of these cards can be linked to an 'ever-increasing anxiety among Taiwanese parents about competition and excellence in the globalising world' (p.4) [13]. Instead of empowering people, this anxiety makes parents vulnerable and invest money and energy in initiatives that might have no positive but potentially negative effects, such as the described sleep deprivation in newborns. Neuroparenting advice that was meant to help deprived children have a better start in life is taken up by high- and middleclass parents as a form of overdrive parenting that is rather geared at exceeding the norm than at safeguarding normal development [12, 14, 18, 48].
Influence on Intimate Relationships Between Parents and Children

The neoliberal view implicit in neuroparenting advice has also been criticized as changing the role of parents and influencing the intimate relationship between parents and children. This supposedly happens in several ways: 1) The process of bonding and other intimate rituals between parents and children gets instrumentalized; 2) Parents are stimulated to adopt the role of managers and view their children as the passive recipients of parents' training program and; 3) The relationship between parents and children is mediated by expert advice, while parental intuitive knowledge is portrayed as insufficient.

The critical literature outlines that for most parents bonding with and stimulating their child comes naturally. Parents cuddle their newborn baby because it feels nice, they play games with their children and make them laugh because that is fun and because they love them, not because neuroscience has appointed these behaviors as conducive for brain development. Parents perform these gestures not because they want to shape their children's brains, but because they find the gestures intrinsically rewarding. Putting these regular daily activities into the context of the need of bonding for the sake of healthy brain development runs the risk of instrumentalizing the loving relationship parents build with their young children. Current intimate rituals of family life might be replaced by the new instrumentalized rituals of neuroparenting, which might aversively affect parent-child relationships [1].

Thornton describes how neuroparenting books are 'dedicated to codifying and specifying the minutiae of practices, expressions, and feelings that constitute effective maternal love' (page 412) [12]. Parenting is presented as a technical process that can be optimized, and where a wrong choice can have disastrous effects. Instructions on how to make eye contact with one's child is a suitable example. When parents make too little eye contact with their children, this can impair language development, bonding and harm children's social, and emotional health. However, when parents make too much eye contact, they risk overstimulating their child [49]. These instructions put great pressure on parents, who must constantly 'calibrate the appropriate quantity and timing of eye contact, precisely navigating the twin dangers of too little and too much' (page 412) 
[12]. While eye contact might be optimised from a neuroscience point of view, parent-child relationships are likely to suffer.

Jacobs and Hens [19] warn that in the current discourse parental love is presented as a duty, as a necessity in the child's development, such as clothing and feeding. This, however, might not only lead to an instrumentalisation of love, but, philosophically speaking, also leads to an absurd situation, because 'love' as such cannot be requested as one cannot will oneself to love [19]. This duty to love can paradoxically disrupt normal bonding by stimulating a mechanic and instrumentalized form of parental love, and result in children lacking in affect $[1,42]$.

Two metaphors seem to depict this new, instrumentalised role of parents rather clearly. Leysen [17] speaks of parents becoming 'parenters': 'a figure performing learned parenting tasks, directed to act in a specific way towards the specific goal of optimal brain development' (p.252). Nadesan [14] describes how parents are made into 'managers' and their children become 'entrepreneurial subjects'. Parents risk to become more focused on their children's brains than on their children as persons and children risk being seen as engineering failures rather than valuable in themselves [14].

In this view of parenting, children are presented as merely passive recipients of parenting, with no preferences, capacities or talents of their own [18]. The parental duty to shape children's brains might result in ever more top-down relationships between parents and children. Instead of fostering familial interaction where parents and children learn from each other [4].

At the same time, parents themselves are considered in constant need of expert knowledge. In order to become able to shape children's brains properly, parents need to comply to expert advice and educate themselves with the latest neurobiological insights. Macvarish called this the expert invasion of family life $[1,31]$. Existing parental knowledge and intuition becomes discarded [17] and parents become mere amateurs whose knowledge about child development and whose cognitive capacities are insufficient to adequately take care of their children.

\section{Critique of the Critical Literature}

The critical studies of neuroparenting perform important pioneering work. However, when reviewing this literature, we noticed a series of shortcomings. In order to further the debate on the worth and the limits of neuroscience informed parenting, it is important to also identify these shortcomings and show where, when, and why neuroscience findings on parenting are not necessarily doomed to lead to a series of problems but could also result in benefits and support child and family well-being. Our impression is that the critical literature solely focuses on potential pitfalls and drawbacks but fails to acknowledge the constructive potential and possible benefits entailed.

We will discuss four shortcomings of the critical literature itself and provide suggestions on how to balance potential harms and pitfalls with possible benefits and advantages of neuroscience-informed approaches to parenting practices. Given the great diversity of neuro-practices, we first question whether the general term of 'neuroparenting' is even useful. We then discuss the proper boundaries of neuroparenting practices. Third, we argue for the importance of a strong evidence base of the neuroparenting advice. Finally, we look at the needs and experiences of parents and adolescents themselves investigating the alleged harm of such practices.

The Generalizability of Results: the Diversity of Neuroparenting

Macvarish [1] was one of the first to coin the term 'neuroparenting' as an overarching concept that describes how childrearing practices are increasingly informed by neuroscientific findings. In this review, we followed this terminology. The advantage is that it becomes apparent how a variety of local practices are part of a larger, social movement with potentially shared risks and drawbacks. However, the concept itself entails the pitfall that the diversity of practices get generalized under the same umbrella. As a consequence, the diversity of implications of various practices tends to get overlooked. The critical literature then risks throwing the baby out with the bathwater, overlooking the potential, benefits and advantages of some neuroscientific findings. The potentially positive impact on parents, educators and the wider social environment is also ignored.

For example, neuroparenting practices vary widely in different countries. In the US, neuroparenting literature on adolescence emphasises the explanation of the deviant functioning of adolescent brains and aims 
to provide a recipe against violent behaviours, like school shootings. [10]. In the Netherlands, by contrast, Van de Werff [4] showed that the neuroscientist Crone's prominent parenting books on adolescence contain an explicitly positive perspective on adolescent brains, as a unique phase of creativity, positive risk taking and social connectivity. This unique phase is presented as offering adolescents benefits on the job market $[4,50]$. These differences in the evaluation of the value and challenges of adolescent brains for young people's behavior are striking. They also cast doubt on the concept of 'neuroparenting' as singular and uniform. Instead, it seems more appropriate to specify the practice a critical debate has in mind.

Similarly, it is striking that most critical reports on early interventions target UK policy documents [6, $15,25,30]$, while in other countries, corresponding debates hardly seem to exist. Have other countries found more sound and agreeable ways to use neuroscience to inform their early childhood policies? Leysen found many differences between Flemish and Anglo Saxon neuroscientific parental educational material. The Flemish tend to focus less on the first three years movement, present less evidence from severe neglect, and had less deterministic views [47]. Again it is not clear that criticism based on the practices in one country generalize to practices in other countries.

\section{Defining Neuroparenting}

Some critical authors define certain parenting practices as neuro-parenting practices, when it seems to us that the impact of the prefix 'neuro' is doubtful. Obviously, the brain is involved in almost all human processes, and most practices impact the brain. However, labelling all kinds of practices that influence brain development as neuro-interventions can be rather confusing and undermine the quality of the critical debate.

Macvarish [1] or example, terms the advice on the importance of breastfeeding and skin-to-skin contact between mothers and newborn babies as forms of neuroparenting. Indeed, these practices are often offered together with neuroscientific evidence that they improve bonding and brain development [1]. But these practices could also be interpreted as part of a countermovement against the medicalization of childbirth. In that sense, dismissing advice on skin contact or breastfeeding as being 'mere neuroparenting', depends itself on a reductionist understanding of the worth of these practices.

Another example comes from Wall's qualitative study on parents' experiences with intensive parenting and the 'brain development discourse' [18]. In her conclusions, Wall argued that the brain development discourse led to an escalation of parenting into hyper-parenting. However, in the quotes of respondents, there is hardly any explicit reference to the brain development discourse or to neuroscience. Respondents mainly talked about intensive parenting and their wish that their children will do well in school, but they did not link this to neuroscientific findings or the brain discourse. Wall seems to equate intensive parenting with neuroparenting, thereby overlooking the possibility that intensive parenting stems from a broader tradition of maximizing a child's chances in a competitive world.

Practices should always be interpreted within their context, paying attention to cultural, familial, and social meanings. In the same way as scientific approaches should not limit their understanding of children's development to brain development, ethical critiques of such approaches should not limit themselves to this focus.

The Importance of the Evidence Base of Neuroparenting Practices

As we outlined earlier, some critical scholars identified a gap between neuroscientific evidence and the neuroparenting advice based on it (see for example: $[23,24,35])$. However, other scholars explicitly state that the scientific validity underlying neuroparenting advice is outside the scope of their critique. Elman [10] and Wall [45] respectively, argue as follows:

It is not the task of this chapter to evaluate the scientific validity of this body of knowledge, but rather to analyse its cultural work. This chapter offers an analysis of the cultural stakes and knowledge-power of brain-based thinking about adolescence as it pervaded popular culture of the 1990s and beyond. (page 133) [10]

My aim here is not to establish the truth or falsity of the scientific claims being made, but rather to suggest that, like other scientific claims, they are not beyond question and 
are influenced by the taken-for-granted social understandings that characterize the dominant discourses of the time. (page 44) [45]

In the debate, there sometimes seems little attention for the scientific underpinning. Bruer, who extensively reviewed the evidence base of the first three years movement [23] noted that most of the attention his work received, was focused on the sociological implications his conclusions had, and only one study critically examined his claims on the lack of scientific base itself [51].

Of all the studies critically examining early intervention policies, only one study [25] included effect studies on whether the policies worked. (This study found that although some of the early intervention programs revealed benefits in relation to 'coping' and 'caring', there was no evidence that irreversible brain damage was prevented, nor that intervention in the first three years is essential. They also found very little evidence that the programs were cost effective [25]).

This disinterest in the validity of scientific foundations is problematic. As Maxwell and Racine [24] point out, epistemic and ethical issues are highly connected. The cultural work and scientific underpinning are connected in important ways. For example, if there was scientific evidence that the heibaika cards discussed before, had the effect that parents hoped (giving their children a head start in life) then the harms of sleep depriving a newborn baby to train their brain could be balanced against the long-term benefits. If there was evidence that hyper-parenting resulted in better developed brains and happier children who become thriving adults, then parents might find it worth sacrificing their own wellbeing. However, when such scientific evidence is missing, or does not support the intervention, this should also have consequences for the ethical debate on whether approaching children in these ways is justifiable or not.

Paying attention to the rigor of the neuroscientific evidence underlying neuroparenting advice is an essential part of sound ethical evaluation, and deepens any analysis that discusses the cultural work of this phenomenon.

\section{Is There Harm Done?}

A key part of ethical decision making is balancing harms and benefits, rather than solely focusing on potential harms. In the current critical debate on neuroparenting, the harms outlined seem mostly hypothetical, and not empirically measured and very little attention to possible benefits. This might result in exaggerating the harms of neuroparenting.

With regard to harm, current critical studies mostly identify possible harms. For example, the potential influence of neuroparenting advice on intimate parent-child relationships. Apart from one qualitative study [18] and some anecdotes from parenting blogs and book reviews $[1,4]$ that show that parents feel pressured and stressed, there is very little evidence that neuroparenting has actually changed such relationships, or that parents indeed feel they are their children's entrepreneurs.

An exception is a qualitative study about what adolescents themselves thought of teenage parenting advice [9]. Focus group interviews with eight 14-years old girls in a high achieving school in London revealed that teenagers considered the rhetoric on teenage brains stereotyping. This neuroscience knowledge did not contribute to their self-understanding, and by contrast they emphasized their own mental autonomy rather than any feelings of being determined by their brains. Social and psychological determinants had much more salience for them in understanding and explaining their behaviour.

We got the impression that many studies focused on the same caricature examples of neuroparenting: the Mozart cd's for newborns, the baby Einstein DVD's, the Allan reports [28, 29], Perry's images of the brains of severely neglected children, the study on blinded kittens. But are there also good practices, and what can we learn from those?

\section{Parents' Views, Needs and Experiences}

In order to ethically evaluate practices of neuroparenting, it is important to also investigate the views and experiences of parents and young people themselves and understand whether and how, neuroparenting meet their needs. Unfortunately, empirical research to this avail is scarce. The studies in this part of this review, present some empirical material. A closer look at this material allows for a more positive understanding of the meaning of neuroscience for parents.

The critical authors mostly emphasise the negative effect of neuroparenting on parent-child relationships. Based on interviews with 14 mothers, Wall 
[18] concluded that neuroscientific insights made them adopt an intensive parenting style, which they found overly stressful. However, some of the quotes demonstrate that mothers feel helped and supported by neuroscience, and that they exhibited an adaptive attitude: adjusting advice to their needs and using them in a pragmatic rather than dogmatic way.

Like the books I read, I look at that and I modify it for my own goals and needs. Even though I think that it is geared to people making their children smarter, to me it is geared to making them happier. I just automatically translate it into my language. [18] (p.256, our emphasis)

Likewise, Chen [13] showed how many of the parents interviewed about the use of the Heibaika cards did not use the cards with the intent of stimulating their children's vision and cognition (as the cards claim to do), but instead used them to play with their children.

The same was found in interviews with 22 Scottish parents who followed a parenting course in which neuroscientific information about child brain development was provided [21]. The authors found that parents adapted or rejected the neuroscientific insight based on their own needs. For example, although they were impressed by the stories of delayed development in Romanian orphanages, parents highlighted that that had very little to do with their own situation. Or, they emphasised that neuroparenting advices depict ideal situations in which a parent has ample time to respond to every cue of her child, while in real life, their children often have to wait a few minutes until parents have time for them. Parents did not think that such brief delays in responding to children's needs would result in any harm [21].

Jacobs and Hens [19] describe the complex relationship parents whose children are diagnosed with autism spectrum disorder have with neuroscientific insights in their child's behavior. Parents described how expert advice on the neuroscience of autism changed their spontaneous relationship with their children. Sometimes this was helpful in understanding and regulating their child's behavior, at other moments, however, they missed the more authentic connection with their child. So, the effect of the neuroscientific expert input in family life, is not black or white, bad or good. More importantly, expert advice does not take effect independent of parents' attitude and willingness to accept or reject it.

Social scientists Mackenzie and Roberts [52] describe their personal experience with brain-based parenting as adoptive parents of traumatized children. They describe how they felt powerless and frustrated by their children's sometimes inexplicable and infuriating behavior. Learning more about the neuroscience of trauma and affect helped them to shift normative attributions of agency and re-evaluate their child's behaviour as the result of their trauma. This resulted in parental relief and rekindled compassion. Brainbased parenting can be neoliberal, entrepreneurial and/or discriminatory, but it can also freconfigure parenting in a positive way.

Parents of adolescents also express that a better understanding of their children's brain helps them develop new parenting skills. Van de Werff cites a book review written by a parent:

When I read this book [53] I realized that it was not so much my child being difficult, the problem was that I didn't understand his behaviour well! (...) The book does not provide solutions for difficulties with adolescent problems, but it helps to understand scientifically how the brain works. As a parent/educator you can use those bits that apply to your situation and that of your child. Since I have the book, we have peace again in our household. This is not because my child is not difficult anymore, but because as a parent I now know how to deal with this behaviour ([54], cited in [4])

Even the rather critical Macvarish [1] cites a parent who reports feeling supported by neuroscience to understand her baby better:

Then I remembered that when a baby is overstimulated, she tells you by turning her head away, closing her eyes, avoiding your gaze, tensing up, or suddenly becoming fussy. It was neat for me to understand what was happening. And it helped me to resist my initial urge to bring baby back by calling her name or waving in front of her face. (p. 90) [1]

Additionally, there are some preliminary findings that suggest that the neuroparenting discourse is not dominant at all among parents. O'Connor and Joffe [20] asked 48 respondent the first four things that 
came to their minds when hearing the concept 'brain research'. Only three respondents mentioned the topic of parenting, indicating that apparently brain research is associated with rather different issues [20].

In contrast to the image presented in the critical literature it seems that parents do not view themselves as passive receivers or helpless victims of neuroparenting advice. Instead they adjust the advice to their needs.

\section{Conclusion: A Guide to Ethically Responsible Neuroparenting}

Neuroscientific research has provided valuable insights into the brain development of young children and adolescents. These insights potentially provide an evidence base for interventions and policies. However, as we have demonstrated, there are many challenges when trying to improve early childhood policies and parenting practices using insights from neuroscientific findings. A first step in doing this in an ethically responsible way, is to become aware of potential pitfalls.

The first pitfall we identified in the critical literature is the gap between science and its applicability. When trying to translate neuroscientific findings to practical advice, policy makers, parents and media should critically examine the neuroscientific findings. One could question for example: How does the researched population compare to the target population of the advice? What biological mechanisms were studied, and what do we know on how these relate to behavioural outcomes? How long-lasting were the effects measured?

Another way to improve the gap between science and practice is by investing in the relationship between scientists, policy makers and media, and develop shared norms for collaboration [55]. Thompson and Nelson [56] pioneered how to improve communication between scientists and policy makers, and argued for setting up shared working groups between both parties.

The second insight from the review was the identification of implicit normative judgments in the translation from science to practices which reinforce existing hierarchies on socio-economic status, ethnicity and gender. Raising awareness about this pitfall might be the first step for more inclusive neuroparenting advice. Moreover, advocates for vulnerable groups and ethicists that uncover implicit normativity should form collaborative groups that translate neurosciences to practices and set neuroscience's agenda based on real-people's needs. Parents, policy makers and media alike should also be encouraged to examine their own, often implicit, norms about parenting, as well as their norms about neuroscientific evidence. Questions for self-examination could be: How do ideas about parenting relate to the current neoliberal culture? Who should define what good parenting is? How seductive are neuroscientific findings?

To further elaborate on this normative self-examination, several scholars $[1,4]$ noticed that the neuroscientific debate seems to be gradually becoming dominant in defining what counts as good parenting. This, however, is problematic. Debates about good parenting should not be reduced to neuroscientific findings. They also require a normative perspective $[4,10,35]$. Neuroscience findings could support parents in achieving what they consider desirable for their children, but it cannot replace the initial discussion on what is desirable and worthwhile in the first place [7, 57]

This normative self-examination also maps onto the third insight that emerges from this review, i.e. the way in which neuroparenting is embedded in a neoliberal culture which emphasizes competition, malleability, self-management and individual responsibility. To better understand the phenomenon of neuroparenting it is important to get to know how parents view these neoliberal norms. Do they explicitly support them, or have they implicitly incorporated these norms? Do they feel empowered by neuroparenting practices, or does it increase their anxiety? Becoming aware of parental needs, both on a personal level as on a societal level, can play an important role in reducing the seductive allure of neuroparenting.

Lastly, we have some recommendations for further critical research on neuroparenting. The hypothesis regarding the influence neuroparenting has on family relationships and parenting values should be further tested. An important limitation of current qualitative studies is that they are mostly done among upper class families. More studies should be conducted on the experiences of families with a lower social economic status. More studies should also be done on how collaboration between neuroscientists and policy makers could be more fruitful and conducive for actual 
families. An examination of best practice could help distill success factors in collaboration. More studies should be done examining neuroparenting practices, whether they are evidence based or practice based. Finally, more research should be done on the experience of parents, adolescents and children.

Acknowledgements The authors received a grant from the Nationale Wetenschapsagenda (NWA), Startimpuls 400.17.602. The authors would like to thank Elizabeth Schier for her valuable feedback.

\section{Declarations}

Conflict of Interest The authors confirm that the manuscript is comprised of original material that is not under review elsewhere, and that the studies on which the research is based has been subject to appropriate ethical review. The authors also declare that they have no competing interests - intellectual or financial - in the research detailed in the manuscript.

Open Access This article is licensed under a Creative Commons Attribution 4.0 International License, which permits use, sharing, adaptation, distribution and reproduction in any medium or format, as long as you give appropriate credit to the original author(s) and the source, provide a link to the Creative Commons licence, and indicate if changes were made. The images or other third party material in this article are included in the article's Creative Commons licence, unless indicated otherwise in a credit line to the material. If material is not included in the article's Creative Commons licence and your intended use is not permitted by statutory regulation or exceeds the permitted use, you will need to obtain permission directly from the copyright holder. To view a copy of this licence, visit http://creativecommons.org/licenses/by/4.0/.

\section{References}

1. Macvarish, J. 2016. Neuroparenting: The expert invasion of family life. London: Palgrave Macmillan.

2. Allen, G. 2008. Early intervention : Good parents, great kids, better citizens early intervention.

3. UNICEF. 2014. Building a happy baby. [Online]. Available: https://www.unicef.org.uk/babyfriendly/wp-content/ uploads/sites/2/2018/04/happybaby_leaflet_web.pdf.

4. van de Werff, T. 2017. Being a good external frontal lobe: Parenting teenage brains. In The human sciences after the decade of the brain, ed. J. Leefmann and E. Hildt, 214231. Amsterdam: Elsevier.

5. Hens, K., D. Cutas, and D. Horstkötter. 2017. Parental responsibility in the context of neuroscience and genetics. New York: Springer.

6. Broer, T., and M. Pickersgill. 2015. Targeting brains, producing responsibilities: The use of neuroscience within British social policy. Social Science and Medicine
132: 54-61. https://doi.org/10.1016/j.socscimed.2015. 03.022 .

7. Mertz, M., H. Kahrass, and D. Strech. 2016. Current state of ethics literature synthesis: A systematic review of reviews. BMC Medicine 14 (1): 1-12. https://doi.org/10. 1186/s12916-016-0688-1.

8. Sofaer, N., and D. Strech. 2012. The need for systematic reviews of reasons. Bioethics 26 (6): 315-328. https://doi. org/10.1111/j.1467-8519.2011.01858.x.

9. Choudhury, S., K.A. McKinney, and M. Merten. 2012. Rebelling against the brain: Public engagement with the 'neurological adolescent.' Social Science and Medicine 74 (4): 565-573. https://doi.org/10.1016/j.socscimed. 2011.10.029.

10. Elman, J. P. 2014. Crazy by design. Neuroparenting and crisis in the decade of the brain. In Chronic youth: Disability, sexuality, and U.S. Media Cultures of Rehabilitation, 131-166. New York: NYU.

11. Bessant, J. 2008. Hard wired for risk: Neurological science, 'the adolescent brain' and developmental theory. Journal of Youth Studies 11 (3): 347-360. https://doi. org/10.1080/13676260801948387.

12. Thornton, D.J. 2011. Neuroscience, affect, and the entrepreneurialization of motherhood. Commun. Crit. Cult. Stud. 8 (4): 399-424. https://doi.org/10.1080/ 14791420.2011 .610327$.

13. Chen, J. Shin. 2021. Beyond black and white: heibaika, neuroparenting, and lay neuroscience. Biosocieties, 16 (1), 70-87. https://doi.org/10.1057/ s41292-019-00180-6.

14. Nadesan, M.H. 2002. Engineering the Entrepreneurial Infant: Brain Science, Infant Development Toys, and Governmentality. Cultural Studies 16 (3): 401-432. https://doi.org/10.1080/09502380210128315.

15. Edwards, R., V. Gillies, and N. Horsley. 2015. Brain science and early years policy: Hopeful ethos or 'cruel optimism'? Critical Social Policy 35 (2): 167-187. https://doi.org/10.1177/0261018315574020.

16. O'Connor, C., and H. Joffe. 2013. Media representations of early human development: Protecting, feeding and loving the developing brain. Social Science and Medicine 97: 297-306. https://doi.org/10.1016/j.socscimed. 2012.09.048.

17. Leysen, J. 2019. Upbringing and neuroscience. Embodied Theory as a Theoretical Bridge Between Cognitive Neuroscience and the Experience of Being a Parent. In Leib - Leiblichkeit - Embodiment Pädagogische Perspektiven auf eine Phänomenologie des Leibes, eds M. Brinkmann, J. Türstig, and M. Weber-Spanknebel, 249263. Wiesbaden: Springer VS.

18. Wall, G. 2010. Mothers' experiences with intensive parenting and brain development discourse. Womens. Stud. Int. Forum 33: 253-263. https://doi.org/10.1016/j.wsif. 2010.02.019.

19. Jacobs, D., and K. Hens. 2018. Love, Neuro-Parenting and Autism : From Individual to Collective Responsibility towards Parents and Children. Anal. J. Gend. Fem. Stud. 10 (December): 102-124.

20. O'Connor, C., and H. Joffe. 2015. How the Public Engages With Brain Optimization: The Media-mind 
Relationship. Sci. Technol. Hum. Values 40 (5): 712743. https://doi.org/10.1177/0162243915576374.

21. Broer, T., M. Pickersgill, and S. Cunningham-Burley. 2020. Neurobiological limits and the somatic significance of love: Caregivers' engagements with neuroscience in Scottish parenting programmes. Hist. Human Sci. 33 (5): 85-109. https://doi.org/10.1177/0952695120 945966.

22. Shonkoff, J.P., and S.N. Bales. 2011. Science Does Not Speak for Itself: Translating Child Development Research for the Public and Its Policymakers. Child Development 82 (1): 17-32. https://doi.org/10.1111/j.1467-8624.2010. 01538.x.

23. Bruer, J.T. 1999. The myth of the first three years: A new understanding of early brain development and lifelong learning. New York: The Free Press.

24. Maxwell, B., and E. Racine. 2012. Does the neuroscience research on early stress justify responsive childcare? examining interwoven epistemological and ethical challenges. Neuroethics 5 (2): 159-172. https://doi.org/10. 1007/s12152-011-9110-z.

25. Wastell, D., and S. White. 2012. Blinded by neuroscience: Social policy, the family and the infant brain. Fam. Relationships Soc. 1 (3): 397-414. https://doi.org/10.1332/ 204674312 X656301.

26. Hubel, D.H., and T.N. Wiesel. 1970. The period of susceptibility to the physiological effects of unilateral eye closure in kittens. Journal of Physiology 206 (2): 419436. https://doi.org/10.1113/jphysiol.1970.sp009022.

27. Perry, B.D. 2002. Childhood Experience and the Expression of Genetic Potential: What Childhood Neglect Tells Us About Nature and Nurture. Brain Mind 3 (1): 79-100.

28. Allen, G. 2011. Early intervention: smart investment, massive savings, the second independent report to Her Majesty's government, London.

29. Allen, G. 2011. Early Intervention: The Next Steps, London. http://www.dwp.gov.uk/docs/early-intervention-nextsteps.pdf.

30. Garrett, P.M. 2018. Wired: Early intervention and the 'Neuromolecular Gaze.' British Journal of Social Work 48 (3): 656-674. https://doi.org/10.1093/bjsw/bcx057.

31. Macvarish, J., E. Lee, and P. Lowe. 2014. The 'First Three Years' Movement and the Infant Brain: A Review of Critiques. Sociology Compass 8 (6): 792-804. https://doi.org/ 10.1111/soc4.12183.

32. Sunderland, M. 2006. The science of parenting. How Today's Brain Research Can Help You Raise Happy, Emotionally Balanced Children. New York: DK Publishing.

33. Lupien, S.J., B.S. McEwen, M.R. Gunnar, and C. Heim. 2009. Effects of stress throughout the lifespan on the brain, behaviour and cognition. Nature Reviews Neuroscience 10 (6): 434-445. https://doi.org/10.1038/nrn2639.

34. Rauscher, F.H., G.L. Shaw, and C.N. Ky. 1993. Music and spatial task performance. Nature 365: 611. https://doi.org/ 10.1038/365611a0.

35. Belsky, J., and M. De Haan. 2011. Annual research review: Parenting and children's brain development: The end of the beginning. J. Child Psychol. Psychiatry Allied Discip. 52 (4): 409-428. https://doi.org/10.1111/j.14697610.2010.02281.x.
36. Bronson, P., and A. Merryman. 2009. NurtureShock: New Thinking About Children. New York: Twelve.

37. Zimmerman, F.J., D.A. Christakis, and A.N. Meltzoff. 2007. Associations between Media Viewing and Language Development in Children Under Age 2 Years. Journal of Pediatrics 151 (4): 364-368. https://doi.org/10. 1016/j.jpeds.2007.04.071.

38. Ferguson, C.J., and M.B. Donnellan. 2014. Is the association between children's baby video viewing and poor language development robust? A reanalysis of Zimmerman, Christakis, and Meltzoff (2007). Developmental Psychology 50 (1): 129-137. https://doi.org/10.1037/a0033628.

39. Snoek, A., and D. Horstkötter. 2018. Ethical issues in research on substance-dependent parents: The risk of implicit normative judgements by researchers. Bioethics 32 (9): 620-627.

40. Wilson, H. 2002. Brain Science, Early Intervention and 'At Risk' Families: Implications for Parents, Professionals and Social Policy. Social Policy \& Society 1 (3): 191-202. https://doi.org/10.1017/s147474640 2003032.

41. Rose, N. and Abi-Rached, J. M. 2013. Neuro: The new brain sciences and the management of the mind.

42. Wall, G. 2018. 'Love builds brains': Representations of attachment and children's brain development in parenting education material. Sociol. Heal. Illn. 40 (3): 395409. https://doi.org/10.1111/1467-9566.12632.

43. Bruer, J.T. 1997. Education and the brain: A bridge too far. Educational Researcher 26: 4-16. https://doi.org/10. 3102/0013189X026008004.

44. Beddoe, L., and E. Joy. 2017. Questioning the uncritical acceptance of neuroscience in child and family policy and practice: A review of challenges to the current doxa. Aotearoa New Zeal. Soc. Work 29 (1): 65. https://doi. org/10.11157/anzswj-vol29iss1id213.

45. Wall, G. 2004. Is your child's brain potential maximized ?: Mothering in an age of new brain research. Atlantis 28 (2): 41-51.

46. Rose, N., and J. Abi-Rached. 2014. Governing through the brain: Neuropolitics, neuroscience and subjectivity. The Cambridge Journal of Anthropology. https://doi. org/10.3167/ca.2014.320102.

47. Leysen, J. 2020. Neuro-stuffed parenthood? Discursive constructions of good parenthood in relation to neuroDiscourse in Flemish social policy documents addressing parents: a case study. Eur. Educ. Res. J., 1-20. https://doi.org/10.1177/1474904120979098.

48. Furedi, F. 2008. Paranoid parenting: Why ignoring the experts may be best for your child. Londen/New York: Continuum.

49. Stamm, J. 2007. Bright from the start: The simple, science-backed way to nurture your child's developing mind from birth to age 3. New York: Gotham Books.

50. Crone, E.A. 2012. Het Sociale Brein van de Puber. Amsterdam: Bert Bakker.

51. Bruer, J. T. 2011. Revisiting 'The Myth of the First Three Years,' Monit. Parents Sci. Evidence, Expert. New Parent. Cult. http://blogs.kent.ac.uk/parentingcultur estudies/files/2011/09/Special-briefing-on-The-Myth. pdf. 
52. Mackenzie, A., and C. Roberts. 2017. Adopting neuroscience: Parenting and affective indeterminacy. Body \& Society 23 (3): 130-155. https://doi.org/10.1177/1357034X17 716521.

53. Crone, E.A. 2008. Het puberende brein. Amsterdam: Bert Bakker.

54. Ptries. 2013. Eindelijk begrijp ik ook mijzelf...! [book review comment]. https://www.bol.com/nl/p/het-puber endebrein/1001004005997720/. Accessed 12 Apr 2019.

55. Spelke, E. 1999. The myth of the first three years: A new understanding of early brain development and lifelong learning. Nature 401 (6754): 643-644.

56. Thompson, R.A., and C.A. Nelson. 2001. Developmental science and the media: Early brain development. American Psychologist 56 (1): 5-15. https://doi.org/10.1037/ 0003-066X.56.1.5.

57. Horstkötter, D. 2019. Self-control enhancement in children, ethical and conceptual aspects. In Shaping children. Ethical and social questions that arise when enhancing the young, ed. S.K. Nagel, 25-41. Switzerland: Springer International Publishing.
Publisher's Note Springer Nature remains neutral with regard to jurisdictional claims in published maps and institutional affiliations.

Anke Snoek , $\mathrm{PhD}$, is a postdoctoral researcher at the Department of Health, Ethics and Society, School of Mental Health and Neuroscience (MHeNS) at Maastricht University, the Netherlands. Her research interests cover questions of agency of vulnerable groups, and research on the intersection of stakeholders needs and evidence based medicine.

Dorothee Horstkötter , $\mathrm{PhD}$, is an assistant professor at the Department of Health, Ethics and Society, School of Mental Health and Neuroscience (MHeNS) at Maastricht University, the Netherlands. Her research interests cover ethical and conceptual questions in mental health and neuroscience. 